\title{
Using fees to reduce bed-blocking: A game between hospitals and care providers
}

Sverre Kverndokk

The Ragnar Frisch Centre for Economic Research

\section{Hans Olav Melberg}

Department of Health Management and Health Economics,

University of Oslo

UNIVERSITY

OF OSLO

HEALTH ECONOMICS

RESEARCH NETWORK

Working paper 2016: 2

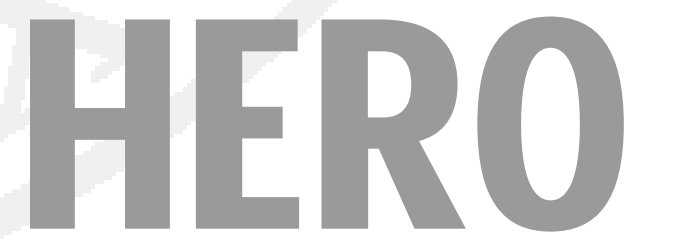




\title{
Using fees to reduce bed-blocking:
}

\section{A game between hospitals and care providers ${ }^{1}$}

\author{
by \\ Snorre Kverndokk ${ }^{2}$ and Hans Olav Melberg ${ }^{3}$
}

January 2016

\begin{abstract}
In 2012, a health reform (the Coordination Reform) was introduced in Norway with an aim to change the incentives of the agents in the health sector to consider the consequences of their actions on other institutions. We study one of the policy measures in the reform, namely the introduction of a fee for bed-blocking in hospitals accompanied by budget transfers from hospitals to municipalities (care institutions). We do this by first introducing a Stackelberg game where the hospital is the leader and the care institution is the follower. The hospital decides the discharge date, taking into account the reactions of the care institution. The model shows that the reform does not necessarily lead to less bed-blocking as this depends on the relative strength of the players' concern for income and patients' health. While a tax gives an incentive to reduce bed-blocking, the effect also depends on the change in the discharge health level. A reasonable outcome is that discharge time goes down, but this may again give an incentive for the care institution to let the patient stay longer at the hospital if it has a positive health effect. This may partly outweigh the effect of the tax. We test the analytical results with data, and find that the reform had a large effect in terms of reducing bed-blocking, and that the effect of the fee becomes significantly larger when we consider the hospitals' strategic behaviour in reducing the discharge time and increasing the number of patients that were reported to be ready for discharge. The interpretations of this may be that the financial incentives count more than the health incentives, or that the health effects of bed-blocking are insignificant.
\end{abstract}

Keywords: Bed-blocking; care services; hospital services; health reform; Stackelberg game.

JEL classifications: H75; I11; I18.

\footnotetext{
${ }^{1}$ This paper is part of the project "Evaluation of the Coordination Reform” funded by the Research Council of Norway. We are indebted to comments from Albert Ma, Tor Iversen and other participants in the projects.

${ }^{2}$ The Ragnar Frisch Centre for Economic Research, Gaustadallèen 21, 0349 Oslo, Norway. Email: snorre.kverndokk@frisch.uio.no.

${ }^{3}$ Institute of Health and Society, University of Oslo, Norway. Email: h.o.melberg@medisin.uio.no. 


\section{Introduction}

Long term care can be provided in different ways such as by family, hospitals as well as by nursing homes and community nursing. Thus different providers of care may meet the patients' need for care, and the organization of long term care also differs for different countries (see e.g., Herolfson and Daatland, 2001; Daatland, 2001). This does not necessarily mean that all types of care such as formal and informal care are complete substitutes, ${ }^{4}$ but to some extent there is substitution between different care services.

How the supply of care in a society is organized may depend on Governmental preferences for instance whether the Government wants a large labour supply by making it possible to combine care giving with participation in the labour market. Community nursing may be one example of this where parts of the care is taken care of by home visits of care personnel employed by the municipality. Economic incentives may also play a role. Even if there is a comprehensive system for publicly provided care for elderly and disabled individuals, we cannot rule out that these incentives matters for the services provided as long as care institutions are restricted by given budgets.

The organization of care services may however not always be optimal due for instance to different institutional barriers. If a supplier is chosen that offer care at a higher cost than other suppliers without doing better on patient health, there is an efficiency loss in the society. Or alternatively, if a supplier is chosen that can compete on costs but will not give the same welfare or health improvements for patient, there may also be a social cost. One concern of social inefficiency that has attracted a lot of attention over some decades is delayed discharge in hospitals for patients in need for care services (see Rubin et al., 1975, for an early study). Delayed discharge leads to bed-blocking, which occurs when patients who have completed treatment at a hospital and is waiting for admittance to a nursing home or home care, stays at the hospital for some time (Mur-Veeman and Govers, 2011). Bed-blocking may give a social cost if it increases waiting time for new patients, if care costs are lower in nursing homes or at home, and if the health consequences for the patient are low or even negative due to susceptibility to new infections. ${ }^{5}$

\footnotetext{
${ }^{4}$ Many relatives may for instance view publicly provided care as insufficient to meet the needs of the patient, particularly with respect to coverage of social needs.

${ }^{5}$ The reasons for bed-blocking are diverse such as internal hospital delays, or waiting for social care assessment, funding or housing, see, e.g., Glasby et al. (2004;2006).
} 
In this paper, we study how economic incentives matter for the organization of care when care can be provided by both hospitals and community nursing homes. The starting point for studying this is the Coordination Reform that was introduced in Norway in January 2012. One of the main goals of the reform was to change the incentives so agents in the system to a larger extent would consider the consequences of their actions on other institutions. The Norwegian municipalities were affected by two main new incentives. First, to stimulate investment in preventive measures, the municipalities have to pay the hospitals $20 \%$ of the costs of treatment of a set of somatic diseases for their inhabitants. ${ }^{6}$ Second, to reduce bedblocking, the municipalities have to pay the hospitals a daily fee of NOK 4,000 (2012) ${ }^{7}$ for patients who are ready to be discharged to municipal care services, but unable to leave because the municipalities do not provide the necessary services. The hospitals have to notify the municipalities in advance of patients who need municipal services, and the fee applies from the first day the patient is considered ready to be discharged. Previous to 2012, there was no fee until the fifth day after the patient was ready to be discharged. The fee was also lower, and it was often not applied since the hospitals were not required to do so. In addition to this, the budgets of hospitals and municipalities were adjusted to compensate for the effects of the fee such that there was an increase in the municipal budget and a decrease in the budgets of the hospitals. ${ }^{8}$

We study the second incentive in this paper, namely the introduction of a fee for bed-blocking in hospitals. By assuming that patients can receive similar services for a certain time period in both hospitals and care institutions, we can analyse how this economic incentive affects the decisions of hospitals and care institutions. We do this by first introducing a Stackelberg game where the hospital is the leader and the care institution is the follower. The hospital decides on the discharge date, taking into account the reactions of the care institution. The model shows that the introduction of a fee does not necessarily lead to less bed-blocking. For the care institution, a higher fee gives an incentive to reduce time at the hospital, while a higher budget gives an incentive the other way around. A higher fee has indeterminate effects on the discharge time for the hospital as it depends on the relative strength of the hospital's concern

\footnotetext{
${ }^{6}$ This was terminated January 12015.

${ }^{7}$ The fee has been adjusted annually and was NOK 4,387 in 2015, approximately 450 Euro (January 2016).

${ }^{8}$ In 2012, NOK 560 million (around 60 million Euro) where transferred from the hospitals budgets to the municipalities so that the municipalities should be able to offer suitable care to the patients after discharge from the hospital. Note that this was only part of the budget transfer from hospitals to municipalities, as the other parts of the reform also involved transfers (https://www.regjeringen.no/no/tema/helse-og-omsorg/helse--ogomsorgstjenester-i-kommunene/samhandlingsreformen-i-kortversjon1/id650137/).
} 
for patients' health and income. If the health effect of bed-blocking is insignificant, the discharge time will go down. This is also supported by lower hospital budgets. A lower discharge time may, however, give an incentive for the care institution to let the patient stay longer at the hospital if it has a positive health effect. This may partly outweigh the effect of the tax. The model demonstrates the importance of considering the strategic behaviour of the hospital when evaluating the policy change.

The empirical importance of this mechanism is assessed in the second part of the paper where we use data on the policy reform to estimate the effect of introducing fees on bed-blocking and the accompanying budget changes, and to what extent the effects were affected by the new incentives to behave strategically. The conclusions are that the reform had a large effect in terms of reducing bed-blocking. The total number of bed-blocking days was for instance reduced by 58\% from 2011 to 2012. Considering the hospitals’ strategic behaviour in reducing the discharge time and increasing the number of patients that were reported to be ready for discharge, the effect of the fee becomes significantly large.

There is an existing literature on the effects of measures to reduce bed-blocking. When it comes to non-financial incentives, Mur-Veeman and Govers (2011) find that setting up intermediate care departments in hospitals to reduce bed-blocking is not sufficient and bedblocking is often caused by lack of buffer management. This is hampered by lack of cooperation between care providers. Fees for bed-blocking was first introduces in Scandinavia. As mentioned above, there was a fee for bed-blocking in Norway before 2012, but this was not introduced in all hospitals. Using a natural experiment due to changes in catchment areas for hospitals, Holmås et al. (2010) find that monetary incentives crowd out agents’ motivation leading to reduced effort in reducing bed-blocking compared to the cases where there were a closer cooperation without punishment. Sweden introduced a reform in 1992 that placed economic responsibility for bed-blockers on municipalities. According to Styrborn and Thorslund (1993), bed-blocking went down, but it was hard to identify the effect of the fee, as other factors were also involved. A fee for bed-blocking was also introduced in England in 2003 (The Community Care Act). The fee was set to $£ 100$ per day ( $£ 120$ in south-east England), but it was introduced together with several other measures (Manzano-Santella, 2010). Godden et al. (2009) find that there is little evidence to conclude that the introduction of the fee has increased public sector efficiency even if there has been a small overall reduction in delayed discharges. McCoy et al. (2007) suggest that the financial investments 
arising from grants (the Delayed Discharge Grant) were more effective than the delayed transfer fee. Most hospitals chose not to charge the fee, but use the grant to fund interventions to reduce delays in discharge. Many patients experienced the hospital discharge negatively, and it has been an increase in the readmissions in hospitals (Bryan, 2010).

The most relevant comparison to the Coordination Reform is the Community Care Act in England. However, as seen from the results above, it is not directly comparable as the fee was lower in England and several other measures were introduced at the same time. In addition, the hospitals used the fee to a lesser extent than in Norway. Thus, we also find higher effects of the fee in Norway than was found in England. Our study shows brings an additional contribution to this field as it analyses the strategic decisions taken by the hospital and the care institution as a game where they have to consider both income and health effects.

In the next section we set up the game between hospitals and care providers and give some predictions of the results of the reform. These predictions are tested in Section 3, while the final section concludes.

\section{A game between a hospital and a care provider}

Below, we introduce a game between a hospital and care providers to study the strategic incentives of the different providers of care services. Both providers of care services care about the health of the patient. Let the health of a representative patient be described by the following function

$$
h=h\left(x^{H}, x^{C}, \delta\right)
$$

where $\mathrm{h}_{x^{H}}^{\prime} \geq 0, \mathrm{~h}_{x^{C}}^{\prime} \geq 0, \mathrm{~h}_{\delta}^{\prime}<0$.

$h$ is the level of health, $x^{H}$ is the level of hospital services and $x^{C}$ is the level of care services. Both hospital and care services can be interpreted as days at the institution or the use of other costly resources. Health is increasing in services but falling in need factors, $\delta$, such as age, prevalence of long-term conditions, rate of informal care etc. 
Note that the individual can only receive one service at the time; either it is in hospital and receives hospital services, or it receives care services from its local community.

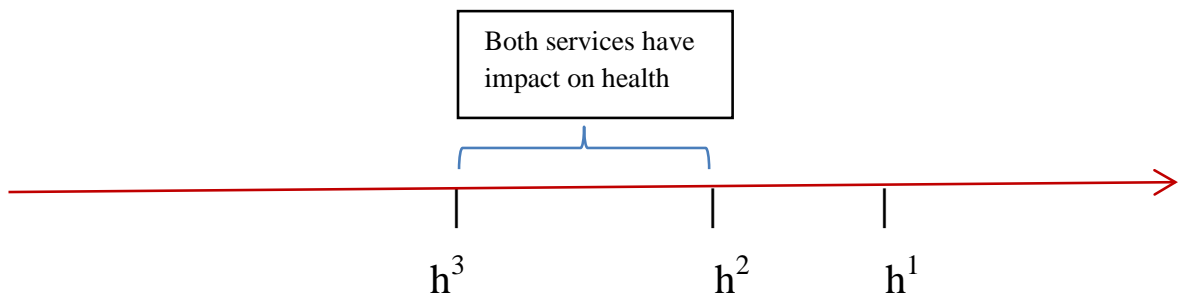

Figure 1: The health thresholds of an individual

Assume now that the individual needs care services if the health level is below a certain value; $h^{1}$. There is also another threshold value, $h^{3}$ : if $h<h^{3}$ where $h^{3}<h^{1}$, hospital services are needed. In this case, care services will not improve the health of the individual, and we assume that no such services are given. Likewise, if $h>h^{2}$, where $h^{2}<h^{1}$, there is no need for hospital services, and they will, therefore, have no impact on the health level. ${ }^{9}$ Thus, in the interval $h^{2}<h<h^{1}$, only care services can improve the health of the individual and no hospital services are, therefore, given. However, there is also an interval described by $h^{3} \leq h \leq$ $h^{2}$, where the medical situation is such that both hospital and care services have a positive impact on the health level, however, not necessary in the same way as one may be more productive than the other. This interval gives a room of freedom for hospitals to decide when to discharge patients. This is illustrated in Figure 1.

Based on this, we can specify the properties of the health function in more detail:

$$
\begin{aligned}
& \mathrm{h}_{x^{H}}^{\prime}>0 \text { and } \mathrm{h}_{x^{H}, x^{H}}^{\prime \prime}<0 \text { for } h \leq h^{2}, \mathrm{~h}_{x^{H}}^{\prime}=\mathrm{h}_{x^{H}, x^{H}}^{\prime \prime}=0 \text { for } h>h^{2} . \\
& \mathrm{h}_{x^{C}}^{\prime}>0 \text { and } \mathrm{h}_{x^{C}, x^{C}}^{\prime \prime}<0 \text { for } h^{3} \leq h<h^{1}, \mathrm{~h}_{x^{C}}^{\prime}=\mathrm{h}_{x^{C}, x^{C}}^{\prime \prime}=0 \text { for } h<h^{3} \wedge h \geq h^{1} .
\end{aligned}
$$

In addition, we assume that hospital and care services are technical substitutes at the margin, i.e., $\mathrm{h}_{x^{H}, x^{C}}^{\prime \prime}=\mathrm{h}_{x^{C}, x^{H}}^{\prime \prime}<0$ for $h^{3} \leq h \leq h^{2}$, meaning for instance that for a higher level of hospital services provided, the effects of additional care services would have lower impact on health.

\footnotetext{
${ }^{9}$ In some cases, the health effect of staying at the hospital may even be negative as there is a risk of being introduced to new infections. 
It follows from the discussion above that there is no exact medical answer to when the patients should be transferred from the hospital to the care institutions. The question we would like to study is, therefore, for what health level would the hospital like to discharge their patients? To study this, we need to say something about the decision structure in hospitals and by care providers.

Inspired by Forder (2009), we assume that the preferences of the hospital and care institution can be described by the following utility functions:

$$
U^{j}=u^{j}\left(n \cdot h\left(x^{H}, x^{C}, \delta\right), m^{j}\right), j=H, \mathrm{C}
$$

where $U_{n h}^{j^{\prime}}>0, U_{m^{j}}^{j^{\prime}}>0, U_{n h, n h}^{j^{\prime \prime}}<0, U_{m^{c}, m^{c}}^{j^{n}}<0, U_{n h, \mathrm{~m}^{\mathrm{C}}}^{j^{n}}=U_{\mathrm{m}^{\mathrm{C}}, n h}^{j^{\prime \prime}}=0 .{ }^{10}$

However, as opposed to Forder (2009), $x^{H}$ and $x^{C}$ cannot be used at the same time by the representative individual.

Let $n$ be the number of patients who are living in a care institution or some kind of sheltered housing, and assume that all patients are equal. Thus, $n \cdot h(\cdot)$ is the sum of welfare of all patients. Further, $m^{j}$ describes the financial situation for the agent, where a better financial situation (e.g., a budget surplus) has a positive impact on the utility. Thus, the agent faces a trade-off between the welfare of the patient and its financial situation.

The budget constraints ${ }^{11}$ for the hospital and the care institution can be outlined as follows:

$$
m^{H}=B^{H}-p^{H} \cdot n x^{H}+t \cdot n x_{t}^{H}
$$

$$
m^{C}=B^{C}-p^{C} \cdot n x^{C}-t \cdot n x_{t}^{H}
$$

where $B^{j}$ is the budget of the agent, which may also describe its capacity constraint, and $p^{j}$ is the unit cost of providing the service, for instance net of co-payment from users. ${ }^{12}$

\footnotetext{
${ }^{10}$ As the cross derivatives are set equal to zero, the utility functions can be specified as additive in the components.

${ }^{11}$ Note that this set up allows for budget deficits. 
The hospital decides the health level, $\bar{h}$, where it discharges the patient. $\bar{x}^{H}$ is the level of hospital services that gives the health level $\bar{h}$. It is reasonable that the hospital chooses $\bar{h}$ so that $h^{3} \leq \bar{h} \leq h^{2}$. When a patient is discharged from the hospital, the care institution can choose to offer services or to let the patient stay longer at the hospital. However, if the care institution decides to let the patient be at the hospital instead of offering care services, it has to pay a fee, $t$, per extra services (for instance per day at the hospital), $x_{t}^{H}$, to the hospital. This fee is set exogenously by the national decision makers. Thus, the care institution decides whether the patient should receive hospital- or care services if $h \geq \bar{h}$.

Based on this we can define the total hospital services given to one patient as

$$
x^{H}=\bar{x}^{H}+x_{t}^{H},
$$

where $\bar{x}^{H}$ follows from the hospitals choice of $\bar{h}$, and $x_{t}^{H}$ is decided by the care institution. In the empirical analysis below, $\bar{x}^{H}$ is called treatment period and $x_{t}^{H}$ is bed-blocking. It follows that

$$
\bar{X}^{H}=\bar{X}^{H}(\bar{h}), \bar{x}_{\bar{h}}^{H^{\prime}}>0
$$

i.e., when the discharge health level of the patient increases, the hospital needs to increase its health services for the patient to reach this level. In the analyses below, we simplify and use $\bar{X}^{H}$ as the decision variable for the hospital.

To study the optimal health service, the starting point is that a patient is in the hospital and the hospital needs to decide when to discharge the patient. The decision will obviously depend on the reactions of the care institution.

\footnotetext{
${ }^{12}$ Activity-based funding for hospitals is not explicitly taken into account. However, the unit cost can be thought of as the cost net of activity based payments.
} 


\section{Solving the model}

The model describes a Stackelberg game where the hospital is the leader and the care institution is the follower. However, the hospital calculates the reactions of the care institution for different levels of $\bar{x}^{H}$.

To solve the model, we therefore, start with the care institution. The care institution decides on its strategy for different levels of $\bar{X}^{H}$, where the level of $\bar{X}^{H}$ is taken as given.

\section{The decisions of the care institution}

For any given level of $t$ and $\bar{x}^{H}$, the institution wants to maximize

$$
U^{C}=u^{C}\left(n \cdot h\left(x^{H}, x^{C}, \delta\right), B^{C}-p^{C} \cdot n x^{C}-t \cdot n x_{t}^{H}\right)
$$

with respect to $x^{C}$ and $x_{t}^{H}$, given equation (5).

Assume first that the care institution decides to offer care services, i.e., $x_{t}^{H}=0$ and $x^{C}>0$. Then the first order condition is

(8) $\frac{\partial u^{C}}{\partial n h} h_{x^{C}}^{\prime}=\frac{\partial u^{C}}{\partial m^{C}} p^{C}$,

i.e., the marginal benefit in utility terms of better health should equal the negative marginal effect on utility of higher spending.

By differentiating (8), we find that the second order condition for maximizing utility is fulfilled, i.e., $A<0$ (see the Appendix).

If the care institution decides to let the patient stay longer at the hospital, i.e., $x_{t}^{H}>0$ and $x^{C}$ $=0$, the first order condition is

(9) $\frac{\partial u^{C}}{\partial n h} h_{x^{H}}^{\prime}=\frac{\partial u^{C}}{\partial m^{C}} t$. 
Again, the marginal effects on utility of a higher health level should equal the negative utility effects of higher costs due to paying the fee.

Again, the second order condition is fulfilled; $B<0$ (see the Appendix).

Let $x^{C^{*}}$ be the solution to equation (8) and $x_{t}^{H^{*}}$ the solution to equation (9). Whether the care institution chooses offering care services or to let the individual stay longer at the hospital depends on the value functions. If

$$
u^{C}\left(n \cdot h\left(\bar{x}^{H}, x^{C^{*}}, \delta\right), B^{C}-p^{C} \cdot n x^{C^{*}}\right)>u^{C}\left(n \cdot h\left(\bar{x}^{H}+x_{t}^{H^{*}}, 0, \delta\right), B^{C}-t \cdot n x_{t}^{H^{*}}\right)
$$

care services should be chosen. If the right hand side is larger, it is optimal to let the individual stay longer at the hospital.

How would the decisions of the care institution depend on the discharge level of health? The effect on the optimal decisions of the care institution can then be found by differentiating the first order conditions.

For $x_{t}^{H}=0$ and $x^{C}>0$, we find by using the second order condition $(A<0)$,

$$
\frac{d x^{C}}{d \bar{x}^{H}}=-\frac{U_{n h, n h}^{C n} n \cdot h_{x^{H}}^{\prime} h_{x^{C}}^{\prime}+U_{n h}^{C^{\prime}} \cdot h_{x^{C}, x^{H}}^{\prime \prime}}{A}<0 .
$$

Thus, a higher level of services provided at the hospital before discharging the patient will reduce the level of care services provided by the care institution.

Further, for $x_{t}^{H}>0$ and $x^{C}=0$, we get by using the second order condition $(B<0)$,

$$
\frac{d x_{t}^{H}}{d \bar{x}^{H}}=-\frac{U_{n h, n h}^{C "} n \cdot\left(h_{x^{H}}^{\prime}\right)^{2}+U_{n h}^{C^{\prime}} \cdot h_{x^{H}, x^{H}}^{\prime \prime}}{B}<0 .
$$


This means that the extra time at hospital after discharge will go down if the discharge health level is higher. This means that the extra time at hospital after discharge will go down if the discharge health level is higher. We further see from (12) and equation (24) in the Appendix (definition of $B$ ) that $-1<\frac{d x_{t}^{H}}{d \bar{x}^{H}}<0$, i.e., it is not full crowding out of hospital services after the discharge date, and the total hospital services, $x^{H}=\bar{x}^{H}+x_{t}^{H}$, will actually be higher. The reason is that hospital services before and after the discharge date do not have symmetric effects on the budget as only the latter has an impact on the spending of the care institution. This gives the following result:

Result 1: When the hospital chooses a higher discharge health level, the services offered by the care institution as well as the number of days at the hospital after discharge will decrease.

Can a higher discharge health level make the care institution change its decision whether to offer care services or to let the patient stay longer at the hospital? This depends on the effect on the value functions in equation (10). As seen from the left hand side of equation, i.e., when the care institution decides to offer services, a higher discharge health level will have a positive effect on the spending, but an ambiguous effect on health as hospital services will increase, but care services will go down. Thus, we cannot say if the value function for the care institution increases if it decides to offer care services. However, if the care institution decides to let the patient stay at the hospital, the value function will actually increase when the discharge health level increases, as both the health level and the financial situation of the care institution improves. Thus, while the opposite is also possible, a higher discharge health level can actually make the care institution change its decision and let the patients stay at the hospital after the discharge date, even if the average time spent at hospital after discharge goes down. This can be summarized in the following result:

Result 2: The care institution may decide to take the patient home after discharge when the discharge health level increase, or alternatively, decide to let the patient stay at the hospital after discharge if the discharge health level is reduced.

\section{The decision of the hospital}

The hospital wants to maximize 


$$
U^{H}=u^{H}\left(n \cdot h\left(x^{H}, x^{C}, \delta\right), B^{H}-p^{H} \cdot n x^{H}+t \cdot n x_{t}^{H}\right)
$$

with respect to $\bar{X}^{H}$, given equations (5) and the reactions of the care institution given by (11) and (12).

The first order condition is

$$
\frac{\partial u^{H}}{\partial n h}\left(h_{x^{H}}^{\prime}\left(1+\frac{\partial x_{t}^{H}}{\partial \bar{x}^{H}}\right)+h_{x^{C}}^{\prime} \frac{\partial x^{C}}{\partial \bar{x}^{H}}\right)=\frac{\partial u^{H}}{\partial m^{H}}\left(p^{H}\left(1+\frac{\partial x_{t}^{H}}{\partial \bar{x}^{H}}\right)-t \frac{\partial x_{t}^{H}}{\partial \bar{x}^{H}}\right)
$$

As for the care institution, the marginal benefit in utility terms of better health should equal the negative marginal effect on utility of higher spending. We know from (11) that when care services are offered, the health effects of offering more hospital services may be outweighed by reduced health effects of reduced care services, i.e., $\frac{d x^{C}}{d \bar{x}^{H}}<0$. Then obviously, the decision depends on the marginal health effects of the different types of services. Further, the costs of offering more hospital services increases with lower total fee payments when the care institution has decided to pay the fee, as we know from (12) that $-1<\frac{d x_{t}^{H}}{d \bar{x}^{H}}<0$. Note, however, that both effects will not happen simultaneously, as we do not have $x^{C}>0$ and $x_{t}^{H}$ $>0$ at the same time.

\section{An increase in the fee}

We now study how an increase in the fee, $t$, affects the decisions of the hospital and the care institution. Let us first start with the care institution.

Assume first that the change does not change the decision to offer services meaning that if for instance the care institution has decided to offer care services, the increase in the fee will not change that decision. Thus, for $x_{t}^{H}=0$ and $x^{C}>0$, a change in the fee does not have any impact. ${ }^{13}$ We therefore study the case where $x_{t}^{H}>0$ and $x^{C}=0$.

\footnotetext{
${ }^{13}$ We return to this at the end of this subsection. 
Differentiating the first order condition (9) and inserting from (24) gives:

$$
\frac{d x_{t}^{H}}{d t}=-\frac{U_{m^{C}, m^{C}}^{C^{n}} n \cdot t x_{t}^{H}-U_{m^{C}}^{C^{\prime}}}{B}<0
$$

We then have the following result:

Result 3: An increase in the fee reduces the services the hospital offers after the discharge time, for instance the number of days the patient stays at the hospital, ceteris paribus.

Let us now look at how the increase in the fee affects the discharge decision of the hospital. To study this, we use the first order condition (14) when $x_{t}^{H}>0$ and $x^{C}=0$, i.e.,

$$
\frac{\partial u^{H}}{\partial n h} h_{x^{H}}^{\prime}\left(1+\frac{\partial x_{t}^{H}}{\partial \bar{x}^{H}}\right)=\frac{\partial u^{H}}{\partial m^{H}}\left(p^{H}\left(1+\frac{\partial x_{t}^{H}}{\partial \bar{x}^{H}}\right)-t \frac{\partial x_{t}^{H}}{\partial \bar{x}^{H}}\right) .
$$

The second order condition for an optimal solution is $C<0$ (see the Appendix).

Differentiating (16) gives: ${ }^{14}$

$$
\frac{d \bar{x}^{H}}{d t}=\frac{\frac{\partial x_{t}^{H}}{\partial t}\left(1+\frac{\partial x_{t}^{H}}{\partial x^{H}}\right)\left(U_{n h, h h}^{H "} n \cdot\left(h_{x^{H}}^{\prime}\right)^{2}+U_{n h}^{H^{\prime}} \cdot h_{x^{H}, x^{H}}^{\prime \prime}\right)+U_{m^{H}, m^{H}}^{H^{\prime \prime}} n \cdot\left(\left(p^{H}-t\right) \frac{\partial x_{t}^{H}}{\partial t}-x_{t}^{H}\right)\left(p^{H}\left(1+\frac{\partial x_{t}^{H}}{\partial x^{H}}\right)-t \frac{\partial x_{t}^{H}}{\partial x^{H}}\right)+U_{m^{H}}^{H^{H}} \frac{\partial x_{t}^{H}}{\partial x^{H}}}{C}
$$

By studying the equation, we see that the effect on the discharge health level and therefore services is indeterminate. The reason for this is that an increase in the fee reduces the time at hospital after discharge, $x_{t}^{H}$, and will therefore have a negative impact on the patient health. ${ }^{15}$

\footnotetext{
${ }^{14}$ The decision of the hospital depends among other things on the characteristics of the reaction function of the care institution to the discharge health level, i.e., $\frac{\partial^{2} x_{t}^{H}}{\partial \bar{x}^{H} \partial t}$. From equation (12), these reactions depend on third derivatives, which are hard to determine. Anyway, it is reasonable that these reactions are not very significant, i.e., $\frac{\partial^{2} x_{t}^{H}}{\partial x^{H} \partial t} \approx 0$. This is assumed in equation (17). The full equation is specified in the Appendix.

${ }^{15}$ Note that in this decision problem, the hospital does not take into account care services after the care institution has brought the patient home. It is concerned about the short term and the medium period before the patient moves back home.
} 
This goes in the direction of higher discharge health services, $\bar{x}^{H}$, to increase the hospital utility. ${ }^{16}$ On the other hand, a higher fee means higher income to the hospital, but a higher fee also reduces the care institutions incentive to let the patient stay at the hospital after discharge, see (15). Both give an incentive for the hospital to reduce $\bar{X}^{H}$ as this will increase services after discharge, see (12). Thus, in general, we cannot therefore tell how the hospital changes the health discharge level due to an increase in the fee. However, if the health effect of staying at the hospital after discharge, $x_{t}^{H}$, is small, i.e., if $\bar{h}$ is close to $h^{2}$ (see Figure 1), the financial incentive will dominate for the hospital, and the result will be a lower discharge health level and health services.

This can be summarized as the following result:

Result 4: An increase in the fee can increase as well as decrease the health discharge level. The outcome depends on the trade-off between better patient health and income. If the health effect of staying at the hospital after discharge is sufficiently small, the discharge health level will go down.

As we in general cannot tell how the hospital changes the health discharge level due to an increase in the fee, we cannot tell how an increase in the fee will affect the decision of the care institution on giving care services or to let the patient stay longer at the hospital. However, based on the discussion above, we may have some interesting conclusions. Even if the care institution decides to take the patient home earlier when a tax is introduced, in a game with several care institutions, more care institutions may decide to let the patient stay at the hospital after a tax is introduced. Thus we may end up in a situation with a shorter stays at the hospital after discharge, but that more patients will stay at the hospital after discharge, even if these stays are short. We summarize this as follows:

Result 5: We cannot rule out that the care institution may change its decision from giving care services to let the patients stay at the hospital after discharge when a fee is introduced.

\section{Changes in budgets}

\footnotetext{
${ }^{16}$ Note that we do not have full crowding out.

Health Economics Research Network at the University of Oslo

ISSN 1501-9071 (print version.), ISSN 1890-1735 (online), ISBN 978-82-7756-252-0
} 
As mentioned in the introduction, the Coordination reform also introduced an income transfer from hospitals to municipalities as more health and care services are meant to be produced in the municipalities. We introduce this in the model as a balanced budget change where the sum of the budgets of the hospital and the care institution is constant $(\bar{B})$.

$$
\begin{aligned}
& B^{H}+B^{C}=\bar{B} \\
& d B^{C}=-d B^{H}>0
\end{aligned}
$$

From the decision problem of the care institution, (7), we find that if the care institution has decided to offer care services $\left(x_{t}^{H}=0\right.$ and $x^{C}>0$ ), we find that the desired effect on care services:

(19) $\frac{d x^{C}}{d B^{C}}=\frac{U_{m^{C}, m^{C}}^{C^{n}} P^{C}}{A}>0$

However, if the care institution decides to let the patient stay at the hospital $\left(x_{t}^{H}>0\right.$ and $x^{C}=$ 0), it will also demand more hospital services:

(20) $\frac{d x_{t}^{H}}{d B^{C}}=\frac{U_{m^{C}, m^{C}}^{C^{\prime \prime}}}{B}>0$

Thus, the income effect leads to a higher production of services.

This gives the following result:

Result 6: A higher budget leads to purchase of more hospital services after discharge, if the care institution decides to let the patient stay at the hospital.

Whether or not the care institution decides to take the patient home after the budget change depends again on the value functions. With a higher budget and the responses above, both patients' health and the financial situation for the care institution will improve, and it is in general not possible to say how this decision will be affected. 
Ow will this affect the hospital's decision on discharge? Let us study the case where $x_{t}^{H}>0$ and $x^{C}=0$, i.e., the care institution has decided to let the patient stay at the hospital after discharge. From the decision problem described above, (13), we find: ${ }^{17}$

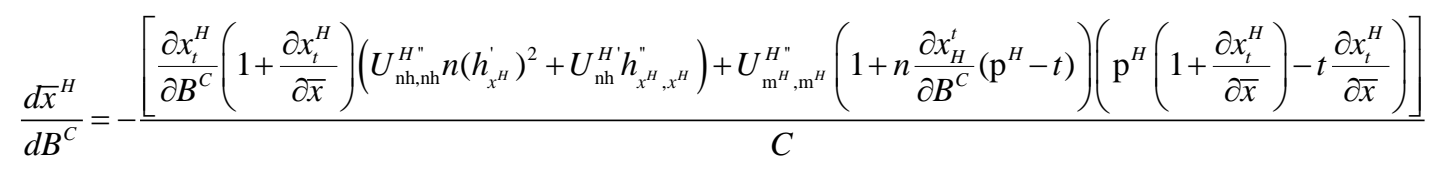

Thus, we find

$$
\frac{d \bar{x}^{H}}{d B^{C}}<0 \quad \text { for }\left(\mathrm{p}^{H}-\mathrm{t}\right) \geq 0
$$

Thus, as long as the fee is not too high, the hospital will reduce the discharge time. Lower hospital budgets will reduce the production of services at the hospital. In addition the hospital knows that parts of this will be outweighed by larger demand for hospital services after discharge as long as the fee is not too large, thus the negative effect of patients' health will be partly reduced. If $\left(\mathrm{p}^{H}-\mathrm{t}\right)<0$, the effect is not clear. The reason is that in this case, the hospital will have a positive income from producing health services after discharge. As long as there is some substitution between services produced before and after discharge, the hospital may have an incentive to cut down the discharge health level. If it is set at the minimum level, $h^{3}$ (see Figure 1), budget changes will have no effect on the discharge time.

This can be summarized as follows:

Result 7: Lower hospital budgets and higher municipal budgets will reduce the discharge health level at the hospital as long as the fee is not too high.

\section{Summarizing the analytical results}

The main results of the analysis can be summarized as follows. The budget change and the change in the fee give incentives in different directions for the care institution. A higher fee gives an incentive to reduce time at hospital after discharge (Result 3), while a higher budget

\footnotetext{
${ }^{17}$ For simplicity, we have set $\frac{\partial^{2} x_{t}^{H}}{\partial \bar{x}^{H} \partial B^{C}} \approx 0$. The exact expression is in the Appendix.

Health Economics Research Network at the University of Oslo

ISSN 1501-9071 (print version.), ISSN 1890-1735 (online), ISBN 978-82-7756-252-0
} 
gives incentives to let the patient stay at the hospital (Result 6). However, the effect on bedblocking also depends on how the hospital changes the discharge time. We find that a higher fee has indeterminate effects on the discharge time as this depends on the hospital's trade-off between patient health and income. If the health effect of staying at the hospital after discharge is sufficiently small, the discharge time will go down (Result 4). This result is also supported by a lower hospital budget (Results 7). A lower discharge time may partly outweigh the effect on bed-blocking if there are positive health effects for the patient to stay at the hospital (Result 1).

Whether the reform changes the behaviour of the care institution so that it changes it decision to let the patient stay at the hospital after discharge or not, is not possible to predict based on general utility functions. However, we cannot rule out that more care institutions decide to let the patient stay at the hospital after discharge as a result of the reform (Results 2 and 5).

\section{Empirical analysis}

\section{Data}

The data on the number of bed-blocking days in Norwegian hospitals was obtained from the Norwegian Patient Registry from 2008 to 2014. This is a comprehensive national registry with information on every admission to all Norwegian hospitals. Altogether the data contains 5,6 million inpatient hospitalizations. The information for each hospital event includes the date for when the patient arrived at the hospital, the diagnosis the patient was given, age, gender, when the hospital considered the patient ready to be discharged and the date when they were in fact discharged. All patients had a discharge date, but only patients believed to be in need of municipal services were recorded with a separate "ready to be discharge date." Most patients do not require municipal services, and of the 5.6 million events, $5.2 \%$ were recorded with a ready to be discharged date (294 965 events). Descriptive statistics for the sample is provided in Table 1.

Table 1: Descriptive statistics of data used in the analysis

\begin{tabular}{cc} 
Regular patients & $\begin{array}{c}\text { Patients discharged to } \\
\text { municipal care }\end{array}$ \\
\hline & $\underline{\text { Reform }}$
\end{tabular}




\begin{tabular}{lrrrr} 
& Before & After & Before & After \\
\cline { 2 - 5 } Number of observations & 3069649 & 2232917 & 102130 & 190997 \\
Average age (years) & 49 & 48 & 77 & 78 \\
Male (\%) & $46 \%$ & $46 \%$ & $41 \%$ & $42 \%$ \\
Avg. length of stay (days) & 4,6 & 4,1 & 14,2 & 7,8
\end{tabular}

The total number of number of bed blocking days due to municipality inability to accept patients who were ready to be discharged, was reduced by 58\% from 2011 to 2012 and it remained significantly lower in all the post-reform period compared to the pre-reform period. (Figure 2). At the same time that the total number of days decreased, the hospitals increased the number of patients reported to be ready to be discharged to the municipalities by $94 \%$ from 2011 to 2012, and it continued to increase in the years after (Figure 3).

Figure 4 shows the average length of a hospital stay decomposed into treatment days and bedblocking days. Average treatment days for each inpatient hospital event has a downward trend for all the years. 


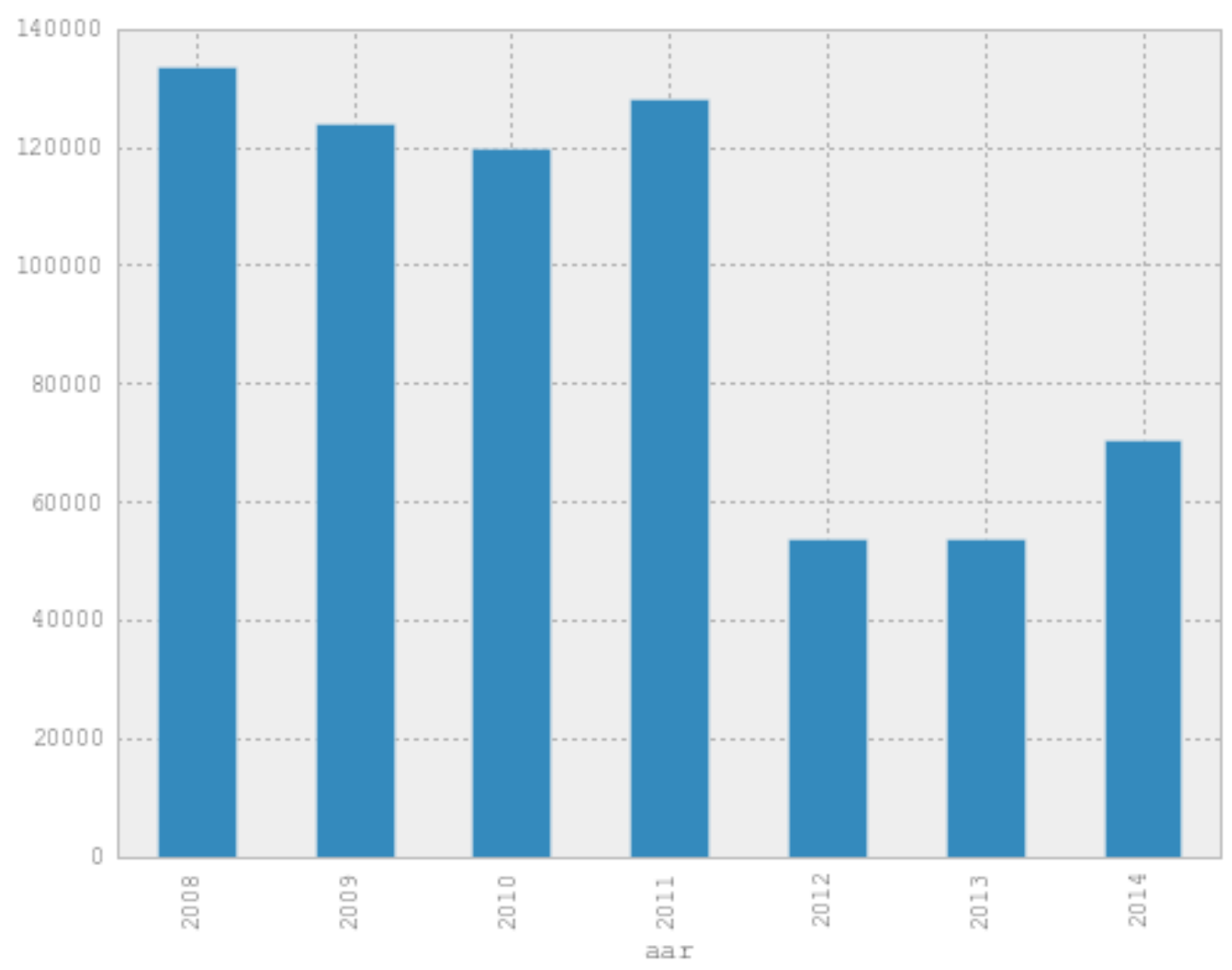

Figure 2: Annual number of bed-blocking days in Norwegian Hospitals

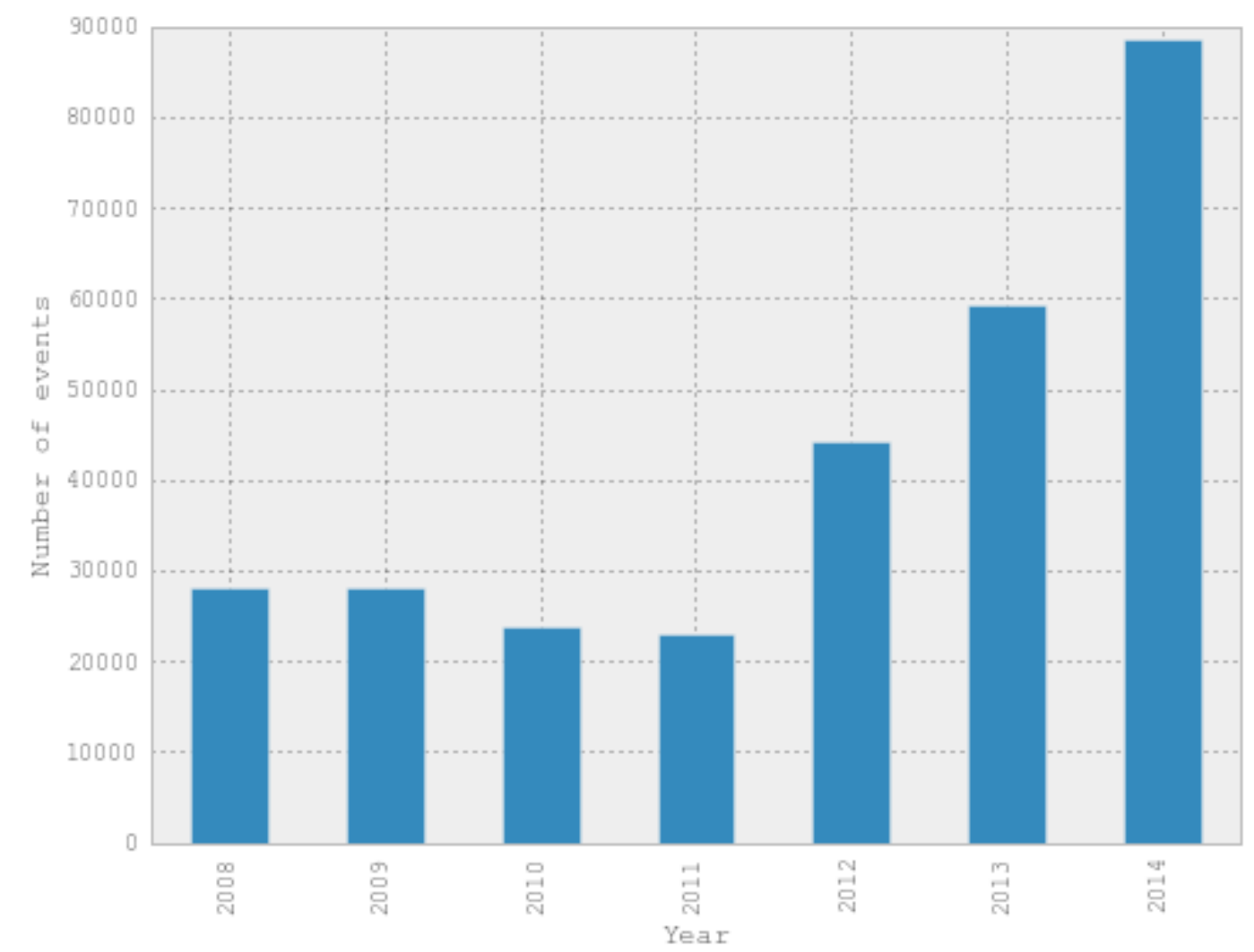

Figure 3: Number of patients the hospitals reported to be ready to be discharged to the municipalities 


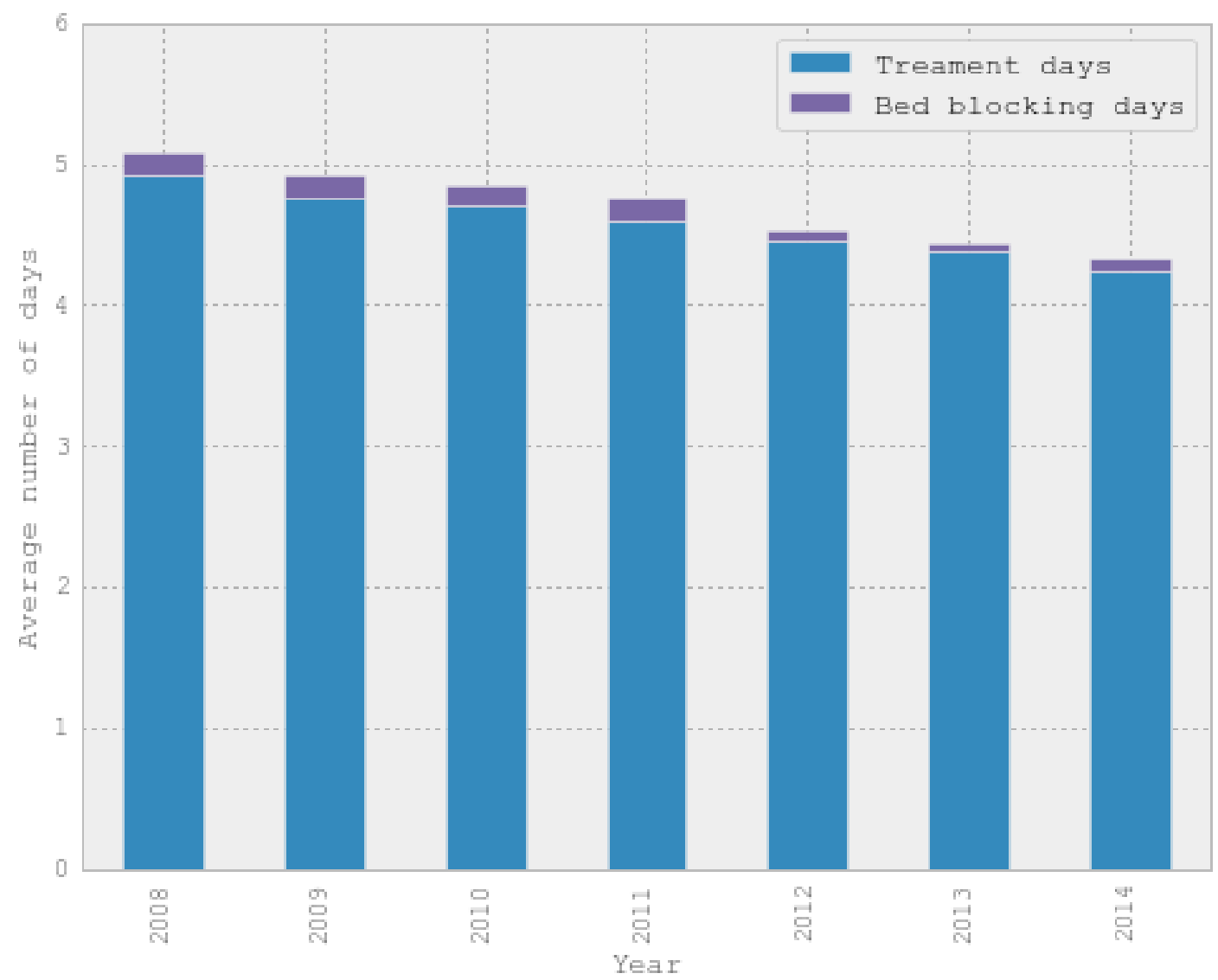

Figure 4: Average length of hospital stays separated into treatment days and bed-blocking days

\section{Method}

Estimating the effect of the reform on the number of bed-blocking days presents several methodological problems. A simple before-and-after comparison of average length of stay among patients who receive municipal care, shows a 45\% decrease (from 14.2 days to 7.8 days on average, see Table 1) and the total number of bed blocking days went down by $58 \%$ between 2011 and 2012 (from 128157 to 53581 days, see Figure 2). However, the directly observed reduction before and after the reform is not a good measure of the causal effect because the reform may have led hospitals to alter their policies on how many patients to record in need of municipal services and how early they are considered ready to be discharged. The theoretical model demonstrated how the fee changed the incentives not only for the municipalities, but also the hospitals. This result is important for the estimation of the causal effect of the reform since if the hospitals start recording more patients as ready to be 
discharged, and earlier, the true effect of the reform is larger than a naive before and after comparison indicates.

In order to estimate whether and how much the hospitals changed their practice in response to the reform, we need an approach that estimates the counterfactual: How would the hospital have behaved if the incentives had not changed? The data contains information about the total length of stay for each patient, but total length of stay in hospital is not controlled by the hospital alone, but also by municipal efforts to accept patients earlier after the introduction of fees. This means that the observed change in total length of stay cannot be used to isolate the effect of the reform on hospital behaviour. Instead of the total length of stay we will focus on the number of treatment days in hospital which is defined as the number of days in hospital before the patient is reported as ready to be discharged (for patients discharged to municipal care) and the actual discharge date for regular patients who are not reported to need municipality care. If the hospital is behaving strategically by labelling patients ready to be discharged earlier than before the reform, the treatment period will decrease.

Focusing on treatment days isolates the variable the hospital controls, but a reduction in the mean number of treatment days before and after the reform is not enough to prove that the hospitals have changed behaviour in response to the reform. First of all, there may be a long term trend towards shorter treatments. Second, confounding factors such as the effects of the other reforms implemented at the same time, could change the composition of patients towards diseases or age groups that affect the mean days in treatment. In order to solve these problems, we estimate a model which predicts how the mean treatment time should have developed in the absence of a reform after adjusting for time trends and compositional changes in the patient group. This model will be used to predict the mean number of treatment days one would expect without the fee.

To model the length of the treatment period we use a Poisson regression model since days in hospitals is a count variable that is skewed with some treatments lasting a long time, but with most treatments lasting only a few days (for more on the Poisson model, see Jones et al., 2013). In order to estimate the reporting practice before the reform, the model was fitted using data on every admission episode before the reform $(\mathrm{t}<22012)$ with gender, age, age squared and the main diagnostic category of the individual as well as a general time trend (to capture trends in in average treatment days over time) as independent variables: 


$$
y_{i, t}=f\left(\alpha+\beta_{1} \text { male }+\beta_{2} \text { age }+\beta_{3} \text { age_squared }+\beta_{4} \text { dignosis }+\beta_{5} \text { year }\right)
$$

The model predicts the number of days in treatment (i.e. before being discharged or reported as ready to be discharged) for a patient with a given gender, age, and main diagnosis. Since we only used data on individuals admitted before the reform to estimate the coefficients, the model represents the practice used by the hospitals before the reform. The results from the regression can then be used to predict the number of days in treatment one would observe for every admission after the reform if the hospitals simply continued with the same reporting practice after the reform:

$\hat{y}_{i, t>2012}=f\left(\alpha+\beta_{1}\right.$ male $+\beta_{2}$ age $+\beta_{3}$ age_squared $+\beta_{4}$ dignosis $+\beta_{5}$ year $)$

In the next step we examine the difference between the predicted and actual number of days in treatment. Given a patient with the same gender, age, main diagnosis, and after adjusting for time trends, the number of days in treatment should be the same both before and after the reform for patients with the same characteristics if the hospitals do not change their behaviour. To examine whether this is the case, we calculate the difference $\left(\Delta_{i, t}\right)$ between the observed and predicted number of days in treatment for every individual admitted after the reform:

$$
\Delta_{i, t}=y_{i, t}-\hat{y}_{i, t}
$$

To examine overall changes in treatment days over time, we aggregate the individual differences between the expected and the actual treatment days and calculate the average deviation between the predicted and the actual days in treatment across all individuals in each year:

$$
\bar{\Delta}_{t}=\frac{\sum_{i=1}^{n} \Delta_{i, t}}{n}=\frac{\sum_{i=1}^{n}\left(y_{i, t}-\hat{y}_{i, t}\right)}{n}
$$

If the difference between the predicted and actual treatment days diverges significantly after the introduction of the reform, this indicates that the hospitals have adapted strategically by reducing the average number of treatment days, i.e. reporting more patients as ready to be 
discharged earlier than they did before the reform. The size of the difference is used to estimate to what extent the reform induced strategic adaptation.

This method is a conservative test of effects in the sense that one would not expect the overall average treatment period to change much since the number of patients affected by the reform (those who need municipal services) is small relative to the number of patients who are not in need of municipal services. As shown by Table 1, only 3.3\% of the hospital events before the reform involved patients who were reported to be in need of municipal services in order to be discharged.

\section{Results}

Table 2 shows the result from the Poisson regression estimating the expected number of treatment days given a patients age, gender, diagnosis and year of admission using all treatment episodes before the reform. Figure 5 shows how the difference between the expected treatment days from the regression and the actual average number of treatment days in the different years. In the pre-reform period, the difference between the expected and the observed number of treatment days was close to zero, while in the post-reform period, the actual number of treatment days was $13 \%$ lower than the observed number of average treatment days for a hospital stay (0.1 days). Finally, Figure 6 shows the predicted and observed number of treatment days before and after the reform for the group that the reform was expected to affect i.e. for only the patients whom the hospital reported to be in need of municipal services in order to be discharged. On average the number of treatment days in this group was reduced by 19\% (1.8 days).

Health Economics Research Network at the University of Oslo 


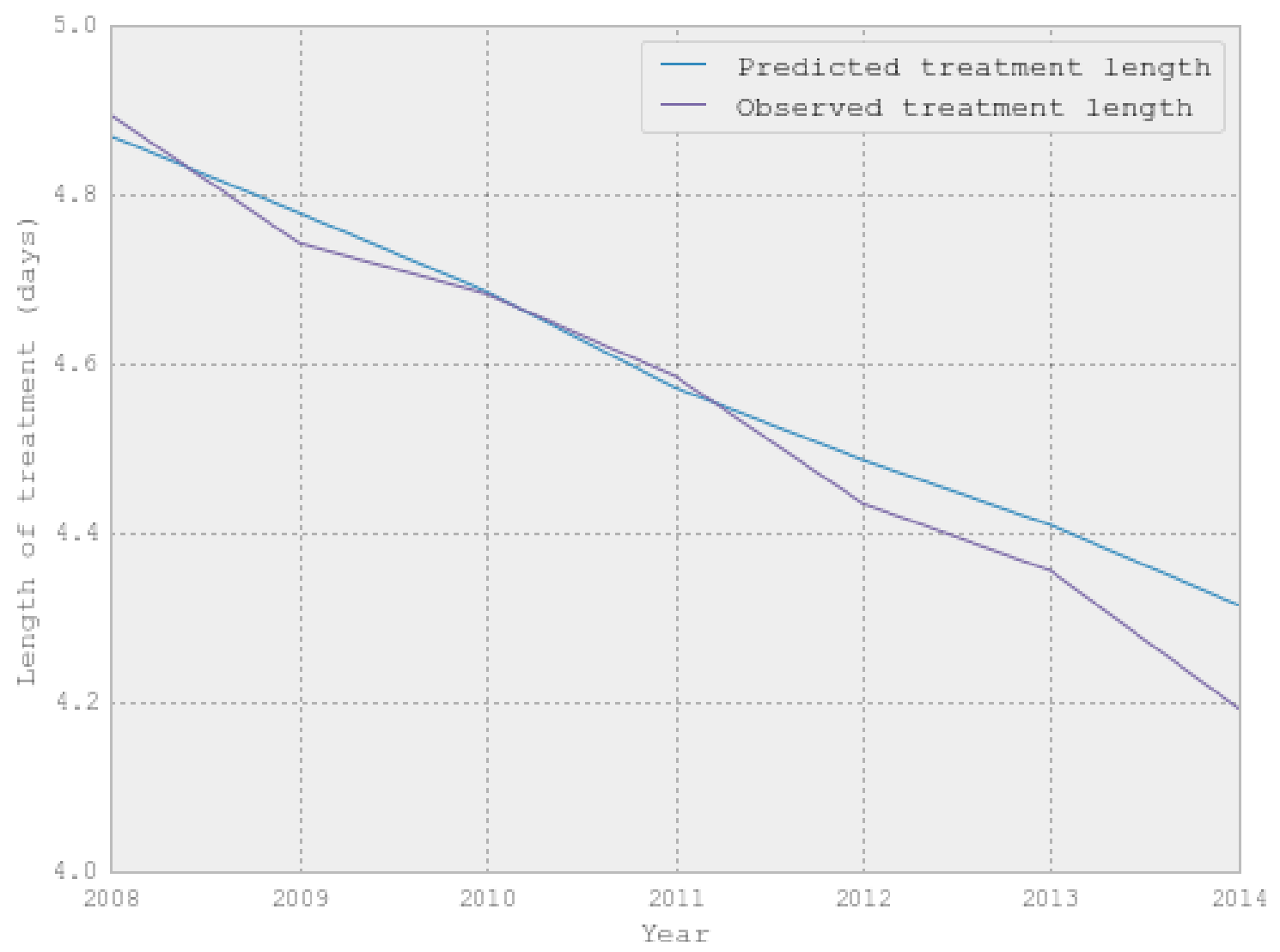

Figure 5: Actual and expected average number of treatment days for an inpatient hospital stay in different years (Expected number of days is based on the regressions model estimated on all pre-reform treatment episodes). 


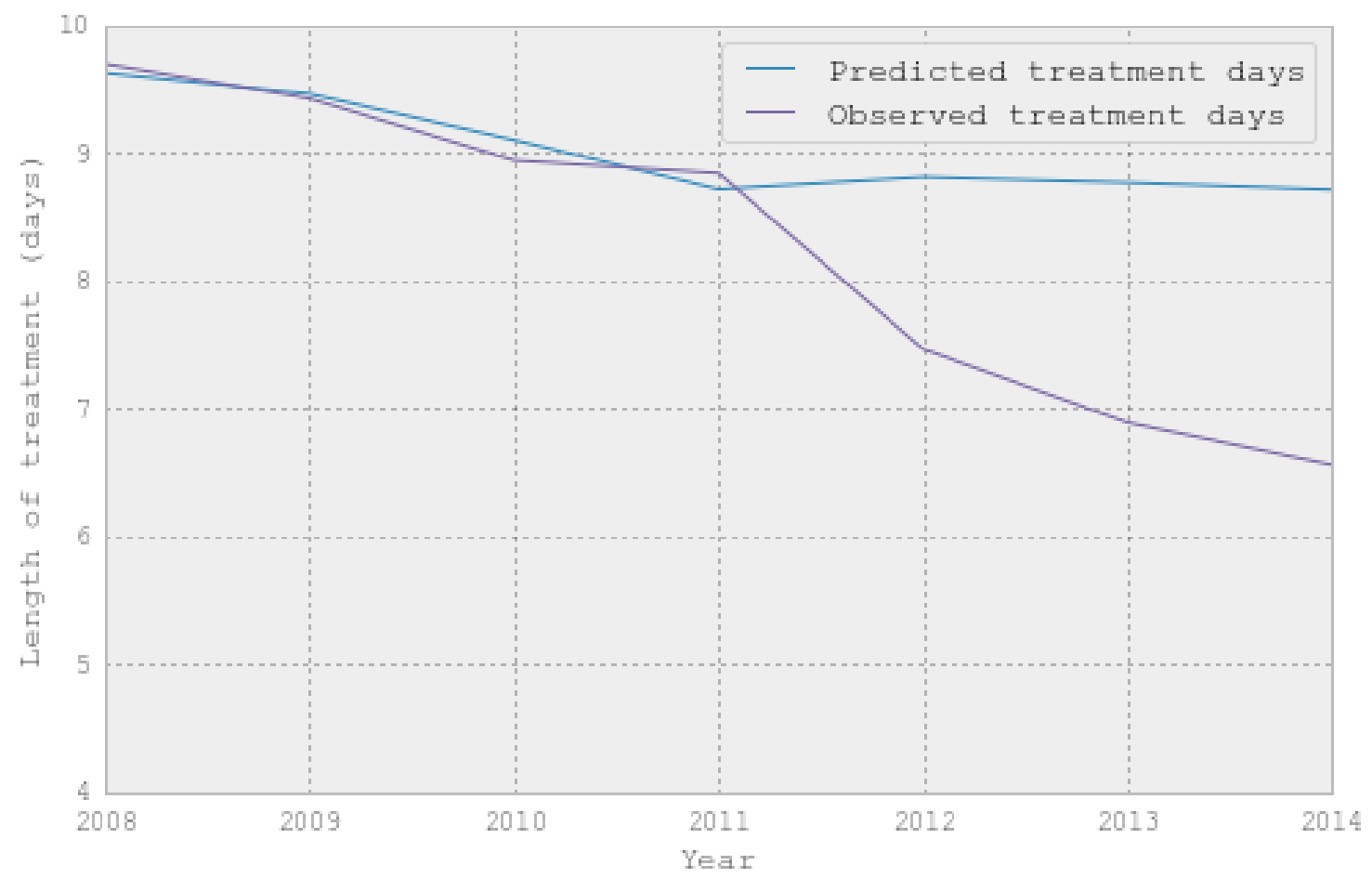

Figure 6: Predicted and observed average number of treatment days for the sub-group of patients who were reported to be in need of municipal services before they could be discharged.

\section{Discussion}

The results show that the introduction of the fee significantly reduced the number of bedblocking days in hospitals. Moreover, the results also show that the hospitals adapted to the reform by reporting more patients as ready to be discharged than before and by reducing the number of treatment days. Based on the expected number treatment days for patients with a given gender, age and diagnosis before the reform, the average length of treatment was reduced by 0.1 days. This is only an average and since most patients were not affected because they did not need municipal services, the reduction among those affected was larger than 0.1 days. For instance, patients with femur fracture who were older than 60 years old, had a reduction in the number of treatment days (i.e. before being reported to be ready to be discharged) by an average of 2,1 days after the reform.

In the year after the reform the total number of bed-blocking days in a year, was reduced from 128000 to 53000 days. This reduction is the net effect of two changes: First, the direct and intended effect which is that the municipalities increased their efforts to accept patients who 
were ready to be discharged. Second, the unintended effect that hospital started to report more patients as ready to be discharged earlier than they had done previously.

To quantify the size of the different effects, one might estimate what had happened to the total number of bed blocking days if the hospital had not changed their reporting practice. The results indicate that in response to the reform, the hospitals reduced the average number of days in treatment (i.e. before the patient was discharged or ready to be discharged) by 0.1 days. If they had continued the old policy, these days would have been classified as treatment days and not bed blocking days. Multiplied by the total number of inpatient hospital stays, the change in reporting practice amounts to adding a total of about 50000 days to the bed blocking statistics. To interpret the size of this number it is useful to recall that previous to the reform the number of bed-blocking days in the year before the reform was close to 130000 . This means that the reform led to an almost $40 \%$ increase in bed blocking days as reported by the hospital, but the observed number fell because the fee also led the municipalities to greatly intensify their efforts to accept patients earlier.

Although the reform clearly underlines the power of financial incentives to promote integrated care, the result does not imply that money is the only useful tool. For instance, previous studies have shown that organizational features, such as having a dedicated personnel and an office to promote speedy transfer from hospital to municipality care, also to had a large effect on the number of bed blocking days in a hospital (Holmås et al. 2010). Other studies have found much weaker effects. For instance, a study of the experience with fees to reduce bed blocking in England, showed no significant effects (McCoy et al, 2007). However, the English fee was far lower than the Norwegian fee and the study also indicated that most English hospitals did not enforce the new system. In Norway the fee was implemented in an organised system of financial transfers and all municipalities and hospitals participated.

\section{Conclusions}

This paper studies the effect on bed-blocking of the Coordination Reform that was introduced in Norway in 2012. To reduce bed-blocking, a fee was introduced (NOK 4000) that the municipalities have to pay the hospitals for patients who are ready to be discharged to 
municipal care services, but unable to leave because the municipalities do not provide the necessary services. To be eligible to receive the fee, the hospitals have to notify the municipalities in advance of patients who need municipal services. In this case, the fee applies from the first day the patient is considered ready to be discharged. The reform also induced a budget change with higher budget transfers to municipalities and lower budgets in hospitals, as more patients are expected to receive care services in the municipalities.

The methodological starting point for this analysis is to consider a game between a hospital and a municipality where the hospital decides on the discharge date (treatment period) and the municipality responds by deciding how long the patient should stay at the hospital after discharge (bed-blocking), when it has to pay a fee to the hospital for bed-blocking. The Stackelberg game shows that a fee gives an incentive to reduce bed-blocking, while a higher budget gives an incentive to let the patient stay at the hospital. However, the effect on bedblocking also depends on how the hospital changes the discharge time. A shorter treatment period will, ceteris paribus, induce more bed-blocking as long as this has a positive health effect for the patient. We find that a higher fee has indeterminate effects on the discharge time as this depends on the hospital's trade-off between patient health and income. If the health effect of staying at the hospital is sufficiently small, the discharge time will go down. This result is also supported by a lower hospital budget. Thus, while the model introduces the different strategic incentives for the hospital and the municipality, the net effect depends on the strength of the different incentives.

To study these incentives, we use data for bed-blocking from the Norwegian Patient Registry from 2008-14. The effect of the reform on bed-blocking was significant. The net effect is that bed-blocking is reduced from 128000 to 53000 days, i.e., 58\%. However, the hospitals changed their practise by reducing the treatment period as well as increasing the number of patients reported ready for discharge. This means that the effect of the fee is relatively strong. The increase in municipal activity was almost the double of what is indicated by the net effect. One interpretation of the results may be that the financial incentives count more than the health incentives, or that the health effects of bed-blocking are insignificant. This relative size of the direct and the indirect effects, illustrate the importance of considering the indirect effect of strategic adaptation when predicting and evaluating policy reforms. 
Appendix 1: Second order conditions, the effect of tax increases, and balanced budget change

\section{Second order conditions}

The second order condition for the maximization problem described by equation (7) when $x_{t}^{H}$ $=0$ and $x^{C}>0$ is fulfilled:

$$
U_{n h, h h}^{C^{n}} n \cdot\left(h_{x^{C}}^{\prime}\right)^{2}+U_{n h}^{C^{\prime}} \cdot h_{x^{C}, x^{C}}^{\prime \prime}+U_{m^{C}, \mathrm{~m}^{C}}^{C^{n}} n \cdot\left(p^{C}\right)^{2} \equiv A<0
$$

If $x_{t}^{H}>0$ and $x^{C}=0$, the second order condition is also fulfilled:

$$
U_{n h, n h}^{C^{\prime \prime}} n \cdot\left(h_{x^{H}}^{\prime}\right)^{2}+U_{n h}^{C^{\prime}} \cdot h_{x^{H}, x^{H}}^{\prime \prime}+U_{m^{C}, \mathrm{~m}^{C}}^{C^{\prime \prime}} \cdot \mathrm{nt}^{2} \equiv B<0
$$

The second order condition for the maximization problem described by equation (13) when $x_{t}^{H}=0$ and $x^{C}>0$ is: ${ }^{18}$

$$
\left(1+\frac{\partial x_{t}^{H}}{\partial x^{H}}\right)^{2} \cdot\left(U_{n h, h h}^{\mathrm{H}} n \cdot\left(h_{x^{H}}^{\prime}\right)^{2}+U_{n h}^{H \cdot} \cdot h_{x^{H}, x^{H}}^{H}\right)+U_{n h}^{H^{\prime}} \cdot h_{x^{H}}^{\prime} \frac{\partial^{2} x_{t}^{H}}{\partial x^{H 2}}+U_{m^{H}, \mathrm{~m}^{H}}^{\mathrm{H}^{\mathrm{H}}} \cdot n \cdot\left(p^{H}\left(1+\frac{\partial x_{t}^{H}}{\partial x^{H}}\right)-t \frac{\partial x_{t}^{H}}{\partial x^{H}}\right)^{2}-U_{m^{H}}^{\mathrm{H}^{H}}(p-t) \frac{\partial^{2} x_{t}^{H}}{\partial x^{H 2}} \equiv C<0
$$

The effect of a tax increase for the discharge time

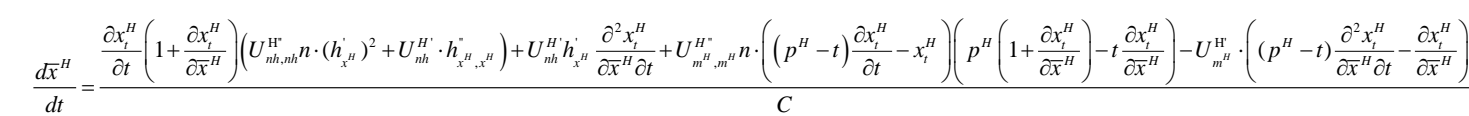

The effect of a balanced budget change for the discharge time

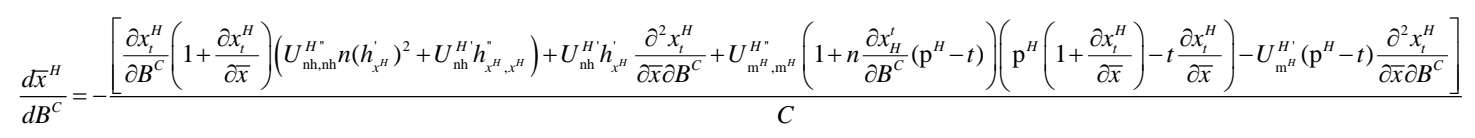

\footnotetext{
${ }^{18}$ Note that the last term is not signed as we do not know $\frac{\partial^{2} x_{t}^{H}}{\partial x^{H 2}}$. However, we know that $C$ has to be negative to find an optimal solution.
} 


\section{Appendix 2: Summary of the Poisson regression}

\begin{tabular}{|c|c|c|c|c|c|c|}
\hline \multirow{2}{*}{$\begin{array}{l}\text { Dep. Variable: } \\
\text { Model: }\end{array}$} & \multicolumn{2}{|c|}{ behandlingsdager } & \multicolumn{2}{|c|}{ No. Observations: } & \multicolumn{2}{|r|}{3171779} \\
\hline & & Poisson & \multicolumn{2}{|c|}{ Df Residuals: } & \multicolumn{2}{|r|}{3171753} \\
\hline \multicolumn{2}{|l|}{ Method: } & MLE & \multicolumn{2}{|c|}{ Df Model: } & \multicolumn{2}{|r|}{25} \\
\hline Date: & Wed, & 06 Jan 2016 & \multicolumn{2}{|c|}{ Pseudo R-squ.: } & \multicolumn{2}{|r|}{$\odot .08171$} \\
\hline Time: & & $18: 51: 53$ & \multicolumn{2}{|c|}{ Log-Likelihood: } & \multicolumn{2}{|c|}{$-1.1749 \mathrm{e}+\Theta 7$} \\
\hline \multirow[t]{2}{*}{ converged: } & \multirow{2}{*}{\multicolumn{2}{|c|}{ True }} & \multicolumn{2}{|c|}{ LL-Null: } & \multicolumn{2}{|c|}{$-1.2795 e+07$} \\
\hline & & & \multicolumn{2}{|c|}{ LLR p-value: } & \multicolumn{2}{|r|}{$\odot . \odot \odot \odot$} \\
\hline \multicolumn{7}{|c|}{ 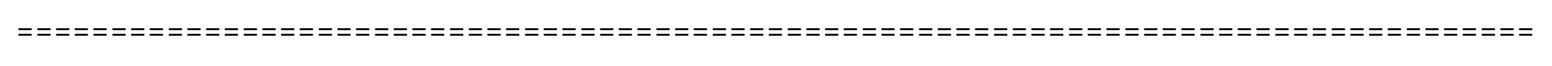 } \\
\hline & coef & std err & z & $P>|z|$ & {$[95 . \odot \% \mathrm{Co}$} & onf. Int.] \\
\hline \multicolumn{7}{|c|}{ 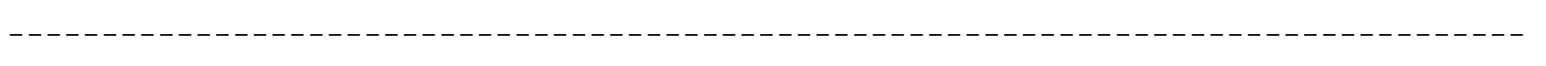 } \\
\hline constant & 40.7879 & $\odot .464$ & 87.847 & $\odot . \odot \odot \odot$ & 39.878 & 41.698 \\
\hline male & 0.0510 & 0.001 & 92.597 & 0.000 & 0.050 & 0.052 \\
\hline alder & 0.0122 & $5.11 \mathrm{e}-05$ & 238.714 & 0.000 & 0.012 & 0.012 \\
\hline alder_squared & $-3.299 e-05$ & $4.77 \mathrm{e}-07$ & -69.117 & $\odot .000$ & $-3.39 e-05$ & $-3.21 e-05$ \\
\hline aar & -0.0198 & $\odot . \odot \odot \odot$ & -85.585 & $\odot . \odot \odot \odot$ & $-\odot .02 \odot$ & $-\odot . \odot 19$ \\
\hline hdgDum_2 & -0.4143 & 0.003 & -118.422 & $0.00 \odot$ & -0.421 & -0.407 \\
\hline hdgDum_3 & -0.6733 & $\odot .002$ & -333.655 & 0.000 & $-\odot .677$ & -0.669 \\
\hline hdgDum_4 & $\odot .1712$ & 0.001 & 145.554 & $\odot .000$ & $\odot .169$ & 0.174 \\
\hline hdgDum_5 & -0.4146 & 0.001 & -344.845 & $\odot . \odot \odot \odot$ & -0.417 & -0.412 \\
\hline hdgDum_6 & -0.1374 & $\odot .0 \odot 1$ & -109.747 & $\odot .0 \odot \odot$ & -0.140 & -0.135 \\
\hline hdgDum_7 & $\odot .0642$ & 0.002 & 36.380 & $\odot .0 \odot \odot$ & $\odot .061$ & $\odot .068$ \\
\hline hdgDum_8 & -0.0465 & 0.001 & -40.549 & $\odot .000$ & -0.049 & -0.044 \\
\hline hdgDum_9 & $-\odot .0879$ & $\odot .002$ & -45.363 & $\odot .00 \odot$ & -0.092 & $-\odot .084$ \\
\hline hdgDum_10 & -0.2229 & $\odot .002$ & -101.044 & 0.000 & -0.227 & -0.219 \\
\hline hdgDum_11 & -0.2016 & $\odot . \odot \odot 2$ & -132.305 & $\odot .0 \odot \odot$ & -0.205 & -0.199 \\
\hline hdgDum_12 & -0.3525 & $\odot .002$ & -141.062 & $\odot .0 \odot \odot$ & -0.357 & -0.348 \\
\hline hdgDum_13 & -0.3115 & $\odot .0 \odot 2$ & -138.646 & 0.000 & -0.316 & -0.307 \\
\hline hdgDum_14 & -0.1442 & 0.001 & -100.441 & $\odot .0 \odot \odot$ & -0.147 & -0.141 \\
\hline hdgDum_15 & 0.3132 & 0.002 & 172.158 & $0.00 \odot$ & 0.310 & 0.317 \\
\hline hdgDum_16 & -0.3283 & $\odot .003$ & -104.537 & 0.000 & -0.334 & -0.322 \\
\hline hdgDum_17 & $\odot .1571$ & $\odot .0 \odot 2$ & 83.082 & $0.0 \odot \odot$ & 0.153 & $\odot .161$ \\
\hline hdgDum_18 & $\odot .3861$ & 0.002 & 228.691 & $\odot .0 \odot \odot$ & 0.383 & 0.389 \\
\hline hdgDum_19 & -0.4283 & 0.003 & -150.632 & $\odot .0 \odot \odot$ & -0.434 & -0.423 \\
\hline hdgDum_21 & $-\odot .3998$ & 0.003 & -153.015 & 0.000 & -0.405 & -0.395 \\
\hline hdgDum_23 & $\odot .8379$ & $\odot .001$ & 641.240 & $\odot .0 \odot \odot$ & $\odot .835$ & $\odot .840$ \\
\hline hdgDum_30 & -0.2869 & $\odot .003$ & -84.831 & 0.000 & -0.294 & -0.280 \\
\hline
\end{tabular}




\section{References}

Bryan, K. (2010): Policies for reducing delayed discharge from hospital, British Medical Bulletin 95(1): 33-46.

Daatland, S. O. (2001): Ageing, families and welfare systems: Comparative perspectives, Zeitschrift für Gerontologie und Geriatrie, 34(1): 16-20.

Glasby, J., R. Littlechild and K. Pryce (2004): Show me the way to go home: a narrative review of the literature on delayed hospital discharges and older people, British Journal of Social Work 34(8): 1189-1197.

Glasby, J., R. Littlechild and K. Pryce (2006): All dressed up but nowhere to go? Delayed hospital discharges and older people, Journal of health services research \& policy 11(1): 5258.

Holmås, T. H., E. Kjerstad, H. Lurås and O. R. Straume (2010): Does monetary punishment crowd out pro-social motivation? A natural experiment on hospital length of stay, Journal of Economic Behavior \& Organization, 75(2): 261-267.

Jones Andrew M., N. Rice, T. Bago d'Uva, and S. Balia (2013): Applied health economics. Routledge.

Forder, J. (2009): Care and hospital utilization by older people: An analysis of substitution rates, Health Economics, 18: 1322-1338.

Herolfson, K. and Daatland, S. O. (2001) Ageing, intergenerational relations, care systems and quality of life - an introduction to the OASIS project, NOVA Report 14/2001, NOVA Norwegian Social Research.

Godden, S., D. McCoy and A. M. Pollock (2009): Policy on the rebound: trends and causes of delayed discharges in the NHS, Journal of the Royal Society of Medicine 102(1): 22-28. 
Manzano-Santaella, A. (2010): Disentangling the impact of multiple innovations to reduce delayed hospital discharges, Journal of health services research \& policy 15(1): 41-46.

McCoy, D., S. Godden, A. M. Pollock and C. Bianchessi (2007): Carrot and sticks? The Community Care Act (2003) and the effect of financial incentives on delays in discharge from hospitals in England, Journal of Public Health 29(3): 281-287.

Mur-Veeman, I. and M. (2011): Buffer management to solve bed-blocking in the Netherlands 2000-2010. Cooperation from an integrated care chain perspective as a key success factor for managing patient flows, International journal of integrated care, 11 (Special 10th Anniversary Edition): e080.

Rubin, S. G. and G. H. Davies (1975): Bed blocking by elderly patients in general-hospital wards, Age and ageing, 4: 142-147.

Styrborn, K. and M. Thorslund (1993): “Bed-blockers”: delayed discharge of hospital patients in a nationwide perspective in Sweden, Health Policy 26: 155-170. 